\title{
THE IMPORTANCE OF DIFFERENT PARAMETERS OF GREATER SCIATIC NOTCH IN SEX DETERMINATION TILL THE AGE OF 20 YEARS
}

\author{
By \\ Adel A. EL-Hawary \\ From \\ Department of Anatomy, Faculty of medicine \\ Mansoura University, Mansoura, Egypt.
}

\begin{abstract}
Various measuments of the greater sciatic notch (G.S.N.) e.g. width, depth and length of the posterior segment of the width were measured, and indices I and II were obtained from lateral radiographs of the pelves of 168 subjecs ( 78 males and 90 females). These subjects ranged in age from one to twenty years. Total and posterior angles were measured in each case.
\end{abstract}

Width, depth and posterior segment length of the G.S.N. were found valueless for sexing purposes before the age of 14 years. After that age till age of 20 years, these parameters become highly effective especially, in females, in sex determination. The length of the posterior segment of the width, posterior angle and idex II were found to be the best paramers, helping to assign the sex of the G.S.N. in different subjects before puberty. One can suggest that the growth of the width of the G.S.N. found in females before puberty occurs primarily in its posterior part.

\section{INTRODUCTION}

The importance of bones, in general, for sex deteremination is well documented both in anatomy (Boucher, 1957: Jit and Singh, 1966; Goldfarb, 1968) and anthropology (Davivongs, 1963). The greater sciatic notch (G.S.N.) attracted attention, as early as 1875 , when Verneau (1875) observed that it was narrower in males and shallower in females. Jovanovic and Zivanovic (1965); Singh and Potturi (1978) and McMinn (1996) stated the influence of that sex on the G.S.N. 
whereas the importance of G.S.N. in differentiation of the pelvic shape was denoted by Hollinshed and Rosse (1985); Llewellyn - Jones (1990); Lindner (1992) and Tortora (1995). Buchsbaum and Schmidt (1993) and Cunningham et al., (1994), also, emphasized the importance of the dimentions of the G.S.N in parturition.

Various meaurements of the G.S.N. such as depth, length of the posterior segment and derived indices I and II in relation to sex determination were used (Williams et al., 1995). Davivongs (1963) found that female greater sciatic notches were deeper as well as wider in Austratian aborigines. This deviation can be regarded as a racial characteritistic. Width and depth of the G.S.N. may be significantly different in bones from different zones (Singh and Gangrade, 1968). These parameters were found to be valueless in sex determination (Singh and Potturi, 1978). Also, index I, which depends on the depth and width of the G.S.N. was accordingly not of much help in the sexing of hip bones. The posterior angle was the best single parameter, the length of the posterior segment and index 11 were high in females, as the widening of the G.S.N. has occurred primarily in its posterior part (Singh and Potturi, 1978).

Most of the previous investigations were focused on the influence of the sex on the various parameters of the G.S.N. in adult human subjects. No attempt has been made to observe the influence of age (before puberty) on the different parameters of G.S.N. in both sexes. Therefore, the present investigation was undertaken to study the changes in parameters of the G.S.N. before puberty as they could be demonstrated radiologically and their relation to sex determination.

\section{SUBJECTS AND METHODS}

168 subjects were selected for this investigation (78 males and $90 \mathrm{fe}$ males). They range in age from one to twenty years (Table 1). They were selected randomly from subjects referred to the Diagnostic Imaging Department, Mansoura Faculty of Medicine Hospital.

The subjects were clinically examined to exclude patients with skeletal delormities especially those of the spine and lower limbs. Other congenital or chronic bone diseases were also excluded. For each subject, a 
plain $\mathrm{x}$-ray of the pelvis in a true lateral position was done. In a perfect true lateral view film, the two greater sciatic notches were superimposed.

The following parameters of the G.SN. were measured (Figs. 1-6) :

1 - The width of the G.S.N. (AB): the distance between the base of ischeal spine (A) and the posterior inferior iliac spine (B).

2- The depth of the G.S.N. (CD): A line drawn from the deepest point of the concavity of the notch (C) perpendicular on the line $A B$, meeting it at the point (D)

3- The posterior segment of the width (BD).

4-Index 1: $\frac{\text { Depth }(C D) \times 100}{\text { width }(A B)}$

5- Idex II : $\frac{\text { Posterior segment } \times 100}{\text { width (AB) }}$

6- Total angle after construction on Radiography the triangle $A B C$ and the depth $C D,<A C B$ denoted total angle.

7- Posterior angle: $<\mathrm{BCD}$.

\section{Statisical analysis :}

Statistical analysis was performed using the student $t$-test paired values and $p$ values of less than 0.05 were considered significant (Armitage, 1983).

\section{RESULTS}

The principal parameters of the G.S.N. and their variabilities were studied in a sample of Egytian population of both sexes at different ages from one to twenty years. The detailed observations are given in Tables 1,2 and in figures 1-13.

\section{The depth of the G.S.N.:}

In subjects before two years, the mean value of the depth of the G.S.N. was $2.55 \pm 2.1 \mathrm{~cm}$ in male and $1.85 \pm 3 \mathrm{~cm}$ in female. In both sexes this parameter showed gradual increase from the age of 6 years till the age of 20 years (Figure. 7). Before 10 years, the difference between the mean value of the depth in both sexes was not significant, although it was greater in males than in females. From 10-14 years, there was overlapping between the mean value of the depth in both sexes. The difference between the value of the depth in both sexes become significant $(p<0.05)$ from the age of 14 years onwards (Table 1 \& Fig. 7 ).

The width of the greater sciatic notch (G.S.N.):

MANSOURA MEDICAL JOURNAL 


\section{THE IMPORTANCE OF DIFFERENT PARAMETERS etc...}

The width of the G.S.N. showed gradual increase in mean value in both sexes, as the age progresses till the age of 20 years (Fig. 8). In the young subject before 8 years, this measurement was found to be greater in males than in females. Between 8 to 14 years, it became greater in females than in males. These differences were not significant. From the age of fourteen years till the age of 18 years, the width of notch was found to be significantly greater in females than in males (Table 1 and Fig. 8).

Posterior segmen of the width of the G.S.N.:

Among the young subject before two years, the mean value of this parameter was greater in female $(1.1 \pm 0.3 \mathrm{~cm})$ than in males $(0.8 \pm 0.4 \mathrm{~cm})$. In males, as the age progressed, this parameter showed slowly and steadily increase in its value (Fig.9), where as in females, it showed rapid and progressive increase in values till the age of 20 years. The main value of the posterior segment was greater in females than in males at different ages. This difference was statistically significant $(p<$ 0.05 ) between both sexes at different ages before 14 years, and it became highly significant $(p<0.001)$ after that age (Table 1 and Fig. 9).

\section{Index I of the G.S.N.:}

Before two years, the mean value of index I was $55.8 \pm 3.5 \mathrm{SD}$ in males and 53.4 $\pm 7.1 \mathrm{SD}$ in females. In the females, this index showed rapid and progressive decrease till the age of 20 years. In males, it showed progressive decrease till the age of 12 years. Thereafter, it increased rapidly and progressively till the age of 20 years. The index I of the notch was significantly

\section{Index II of the G.S.N.:}

In young subjects before two years the mean value of index II was $29.4 \pm 3.8$ SD in males and $42.8 \pm 3.9$ in females. In males this index decreased gradually in its value till the age of 18 years, whereas in females it decreased gradually in its value till the age of 12 years after which it showed rapid increase in its value till the age of 20 years. Index II in females was significantly greater than that of males at Jiff age erent ac groups (Table II \& Fig. 11)

\section{The total angie of the G.S.N.:}

At different age groups, the total angle is greater in females than in males. Before 12 years, it seems to 
be stationary in its value in both sexes, ranged between 81.7 to 82.5 in males and 87.9 to 86 in females. After that age, the valu e of this angle showed progressive and significant increase in females, and males till the age of 20 years. (Table 11 \& Fig. 12)

The posterior angle of G. S. N.: In young subjects before two years, The man value of the posterior angle was $25.6 \pm 7.2$ in males and $36.5 \pm 3.5$ in females. In males, this angle decreased gradually in its value till the age of 20 years, whereas in females it showed gradual decreases in its value till the age of 20 years. Posterior angle value in females is significantly greater than that of males at different age groups. (Table II and Fig. 13).

Table (I) : The means and standard deviations of the various parameters of the greater sciatic notch (G.S.N.) (Depth, width, posterior segment and index I).

\begin{tabular}{|c|c|c|c|c|c|c|c|c|c|c|}
\hline \multirow{2}{*}{$\begin{array}{c}\text { Age } \\
\text { group } \\
\text { (years) }\end{array}$} & \multicolumn{2}{|c|}{$\begin{array}{c}\text { No. of } \\
\text { subjects }\end{array}$} & \multicolumn{2}{|c|}{ Depth } & \multicolumn{2}{|c|}{ Width } & \multicolumn{2}{|c|}{ Posterior segment } & \multicolumn{2}{|c|}{ Index I } \\
\hline & F. & м. & F. & M. & F. & M. & F. & M. & F. & M. \\
\hline $0.2 y$ & 6 & 6 & $2.55 \pm 2.1$ & $1.85 \pm 3.8$ & $2.6 \pm 4.2$ & $2.7 \pm 1.8$ & $1.1 \pm 3.6^{*}$ & $0.8 \pm 3.4^{\prime \prime}$ & $53.4 \pm 7.1$ & $55.8=3.5$ \\
\hline $2-4 y$ & 10 & 8 & $1.8 \pm 3.2$ & $1.6 \pm 2.8$ & $3.1 \pm 2.6$ & $3.4 \pm 2.1$ & $1.25 \pm 4.5^{\circ}$ & $0.9 \pm 4.1^{*}$ & $53.1 \pm 7.3$ & $54.3 \pm 4.3$ \\
\hline $4-6 y$ & 9 & 8 & $2.15 \pm 4.2$ & $1.45 \pm 4.2$ & $3.8 \pm 1.8$ & $3.4 \pm 2.8$ & $1.3 \pm 4.1^{\bullet}$ & $0.95 \pm 2.6^{\circ}$ & $51.8 \pm 2.6$ & $54 \pm 3.9$ \\
\hline $6-8 y$ & 7 & 9 & $2.25 \pm 0.2$ & $2.05 \pm 3.2$ & $4.1 \pm 1.6$ & $4.2 \pm 3.4$ & $1.4 \pm 3.1$ & $1.6 \pm 7.1^{\circ}$ & $51.4 \pm 7.7$ & $53 \pm 3.6$ \\
\hline $8-10 y$ & 8 & 6 & $2.45 \pm 1.2$ & $2.45 \pm 3.1$ & $4.8 \pm 3.2$ & $4.6 \pm 2.8$ & $1.65 \pm 3.6^{\circ}$ & $1.1 \pm 3.1^{*}$ & $50.8 \pm 7.4$ & $53.5 \pm 4.1$ \\
\hline $10-12 y$ & 10 & 8 & $2.6 \pm 0.8$ & $2.65 \pm 3.1$ & $5.4 \pm 2.1$ & $4.9 \pm 1.8$ & $1.75 \pm 4.2^{\circ}$ & $1.05 \pm 4^{*}$ & $50 \pm 8.3$ & $52.1 \pm 4.9$ \\
\hline $21-14 y$ & 7 & 8 & $2.8 \pm 3.6$ & $28 \pm 3.6$ & $5.6 \pm 3.8$ & \pm 5.21 .8 & $1.95 \pm 0.6$ & $1.05 \pm 3.1^{\prime}$ & $49.5 \pm 7.5$ & $54.2 \pm 5.9$ \\
\hline $14-16 y$ & 13 & 8 & $3.1 \pm 1.2^{*}$ & $2.9 \pm 1.8^{\circ}$ & $6.0 \pm 5.1^{\circ}$ & $5.3 \pm 4.1^{*}$ & $2.3 \pm 3.1^{\circ}$ & $1.15 \pm 4.5^{\circ \bullet}$ & $48.3 \pm 10.3^{\circ}$ & $58 \pm 7.9^{\circ}$ \\
\hline $16-18 y$ & 9 & 8 & $3.2 \pm 4.2^{\circ}$ & $2.85 \pm 1.1^{\circ}$ & $61 \pm 3.1^{\circ}$ & $5.4 \pm 3.2^{*}$ & $2.4 \pm 2.8^{\circ *}$ & $1.1 \pm 2.1^{* *}$ & $47 \pm 9.2^{\circ}$ & $59.6 \pm 7.3^{*}$ \\
\hline $18-20 y$ & 11 & 9 & $3.25 \pm 2.1^{\circ}$ & $2.8 \pm 3.5^{\circ}$ & $6.2 \pm 4.2^{*}$ & $6.6 \pm 3.8^{\circ}$ & $2.5 \pm 1.8^{* *}$ & $1.15 \pm 2.8^{* 0}$ & $46 \pm 4.1^{\circ}$ & $59.9 \pm 4.9^{\circ}$ \\
\hline Total No & 90 & 78 & & & & & & & & \\
\hline
\end{tabular}


Table (II): The means and standard deviations of the various parameters of the greater sciatic notch (G.S.N.) (index ii, total angle and posterior angle).

\begin{tabular}{|c|c|c|c|c|c|c|c|c|}
\hline \multirow{2}{*}{$\begin{array}{c}\text { Age } \\
\text { group } \\
\text { (years) }\end{array}$} & \multicolumn{2}{|c|}{$\begin{array}{c}\text { No. of } \\
\text { subjects }\end{array}$} & \multicolumn{2}{|c|}{ Index II } & \multicolumn{2}{|c|}{$\begin{array}{r}\text { Total angle } \\
\text { (in degrees) }\end{array}$} & \multicolumn{2}{|c|}{$\begin{array}{l}\text { Posterior angle } \\
\text { (in degrees) }\end{array}$} \\
\hline & F. & M. & F. & M. & F. & M. & F. & M. \\
\hline $0.2 y$ & 6 & 6 & $42.8 \pm 3.9$ & $29.4 \pm 3.8^{*}$ & $85 \pm 4.5$ & $82.5 \pm 4.5$ & $36.5 \pm 3.5^{\circ}$ & $25.6 \pm 7.2^{*}$ \\
\hline $2-4 y$ & 10 & 8 & $38.6 \pm 3.8^{*}$ & $26.1 \pm 4.5^{*}$ & $84.8 \pm 4.4$ & $83.8 \pm 4.6$ & $36.5 \pm 4.1^{*}$ & $25.5 \pm 4.6^{*}$ \\
\hline $4-6 y$ & 9 & 8 & $34.9 \pm 4.6^{*}$ & $23.9 \pm 4.6^{*}$ & $85.5 \pm 5.5$ & $83.2 \pm 5.8$ & $36.5 \pm 4.4^{*}$ & $25.1 \pm 3.1^{*}$ \\
\hline $6-8 y$ & 7 & 9 & $\pm 34.13 .9^{*}$ & $24.1 \pm 4.5^{*}$ & $86 \pm 68$ & $82.1 \pm 5.6$ & $35.5 \pm 4.3^{*}$ & $23.3 \pm 4.1^{*}$ \\
\hline $8-10 y$ & 8 & 6 & $33.7 \pm 4.2^{*}$ & $23.9 \pm 5.1^{*}$ & $85 \pm 4.7$ & $81.7 \pm 5.1$ & $34.7 \pm 4.2^{*}$ & $22.6 \pm 5.2^{*}$ \\
\hline $10-12 y$ & 10 & 8 & $32.8 \pm 4.4^{*}$ & $21.2+3.8^{*}$ & $83.9 \pm 6.2$ & $81.7 \pm 6.4$ & $33.1 \pm 3.6^{*}$ & $21.7 \pm 4.8^{*}$ \\
\hline $21-14 y$ & 7 & 8 & $34.8 \pm 5.4^{*}$ & $21.1 \pm 3.4^{*}$ & $84 . \pm 4.5$ & $78.9 \pm 5.7$ & $33.7 \pm 4.7^{*}$ & $21.5 \pm 5.1^{*}$ \\
\hline $14-16 y$ & 13 & 8 & $38.3 \pm 7.4^{* *}$ & $20.1 \pm 4.5^{* *}$ & $85.4 \pm 5.1^{*}$ & $76 \pm 6.2^{*}$ & $37.5 \pm 5.0^{* *}$ & $19.7 \pm 3.6^{* *}$ \\
\hline $16-18 y$ & 9 & 8 & $39.3 \pm 6.9^{* *}$ & $19.5 \pm 3.9^{* *}$ & $86.4 \pm 8.2^{*}$ & $72.1 \pm 8.2^{*}$ & $39.9 \pm 5.0^{* *}$ & $18.2+3.4$ \\
\hline $18-20 y$ & 11 & 9 & $39.9 \pm 5.9^{* *}$ & $20.5 \pm 3.2^{* t}$ & $88.5 \pm 8.1^{*}$ & $80.3 \pm 8.2^{*}$ & $41.2 \pm 4.1^{* *}$ & $15.2 \pm 4.5^{* *}$ \\
\hline Total No & 90 & 78 & & & & & & \\
\hline
\end{tabular}

Vol. 30 , No. 1 \& 2 Jan. \& April, 2000 


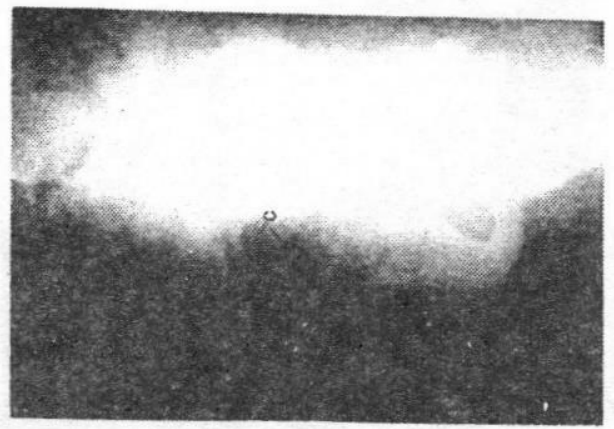

Fig. 1: Photography of true lateral view radiograph of the pelvis of male subject aged two years at the region of G.S.N

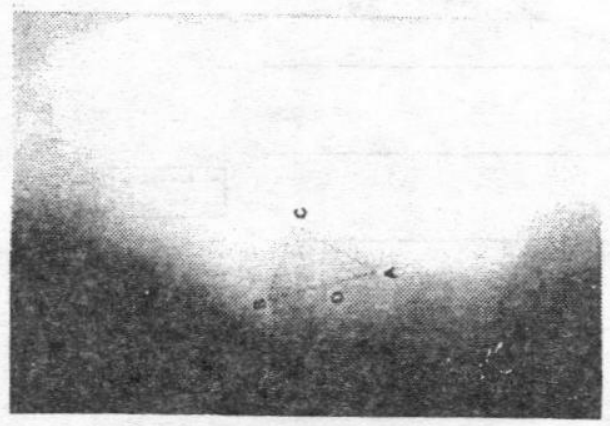

Fig. 3 : Photography of true lateral view radiograph of the pelvis of male subject aged 12 years at the region of G.S.N.

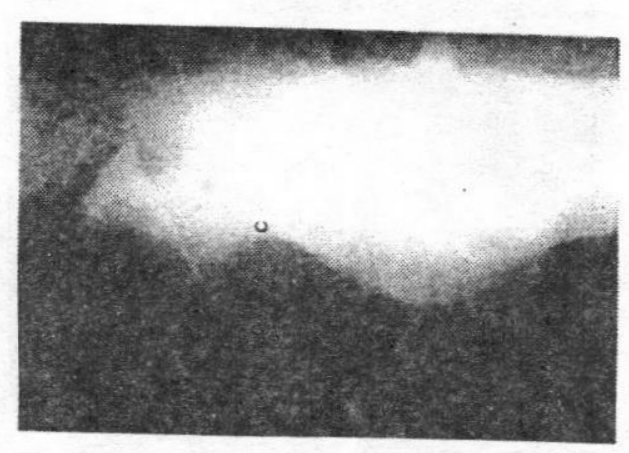

Fig. 2 : Photography of true lateral view radiograh of- the pelvis of female subject aged 3 years at the region of G.S.N

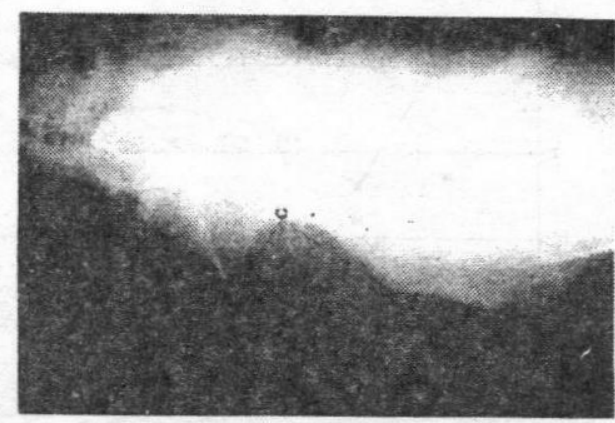

Fig 4 : Photography of true lateral view radiography of the pelvis of female subject aged 14 years at the region of G.S.N.

MANSOURA MEDICAL JOURNAL 


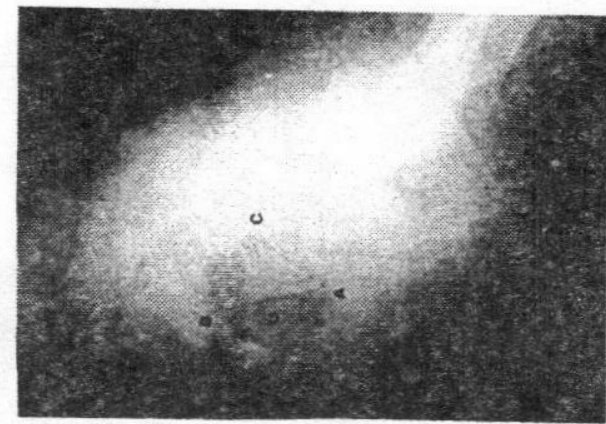

Fig. 5 : Photography of true lateral view radiography of the pelvis of male subject aged 18 years at the region of G.S.N.

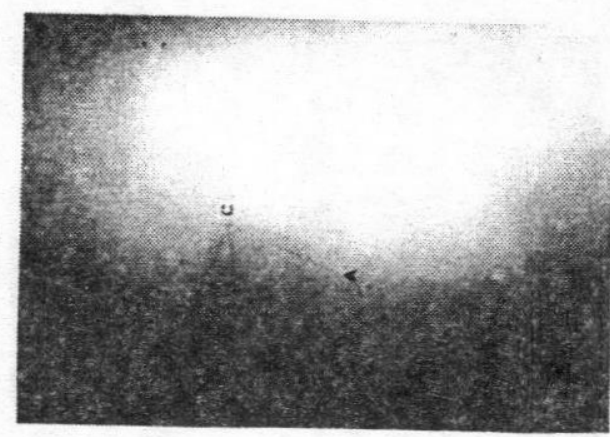

Fig. 6 : Photography of true lateral view radiography of the pelvis of female subject aged 20 years at the region of G.S.N.

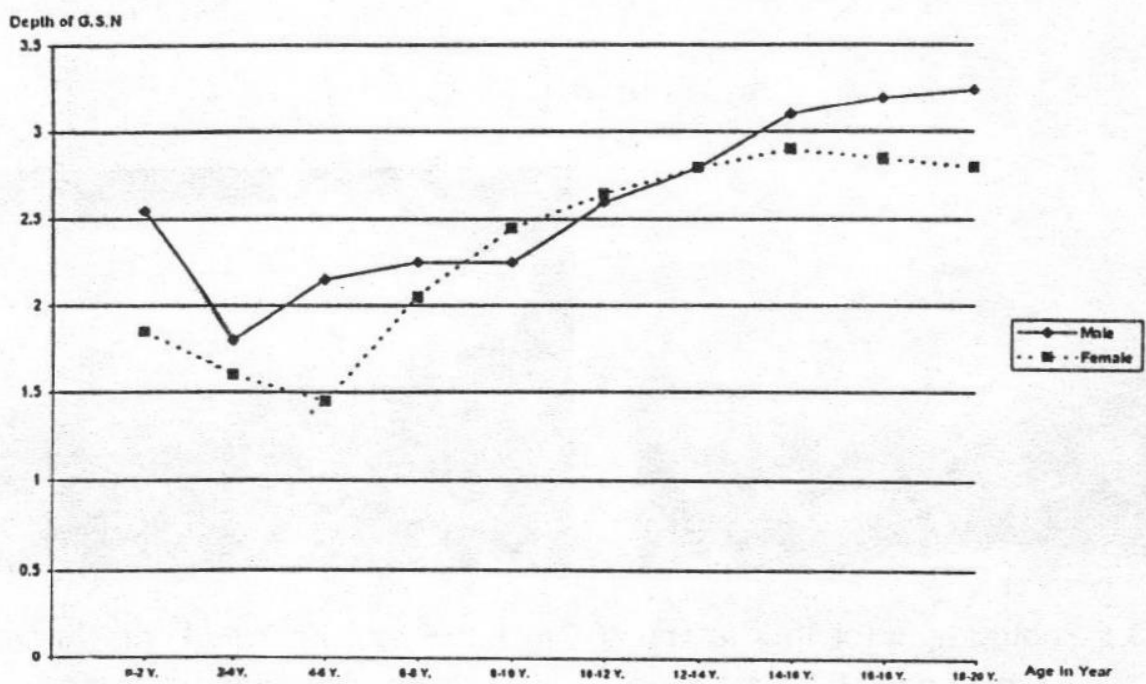

Fig. 7 : Depth of G.S.N. among males and females in different age groups.

Vol. 30 , No. $1 \& 2$ Jan. \& April, 2000 


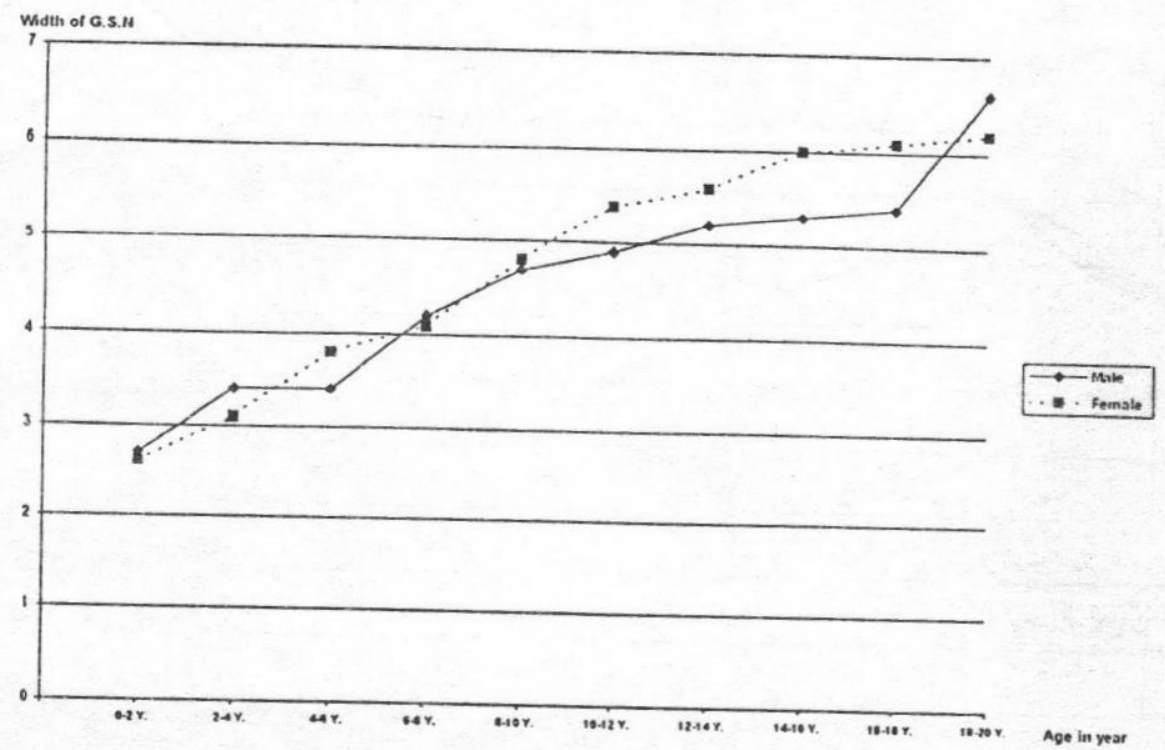

Fig. 8 : Width of G.S.N. among males and females in different age groups.

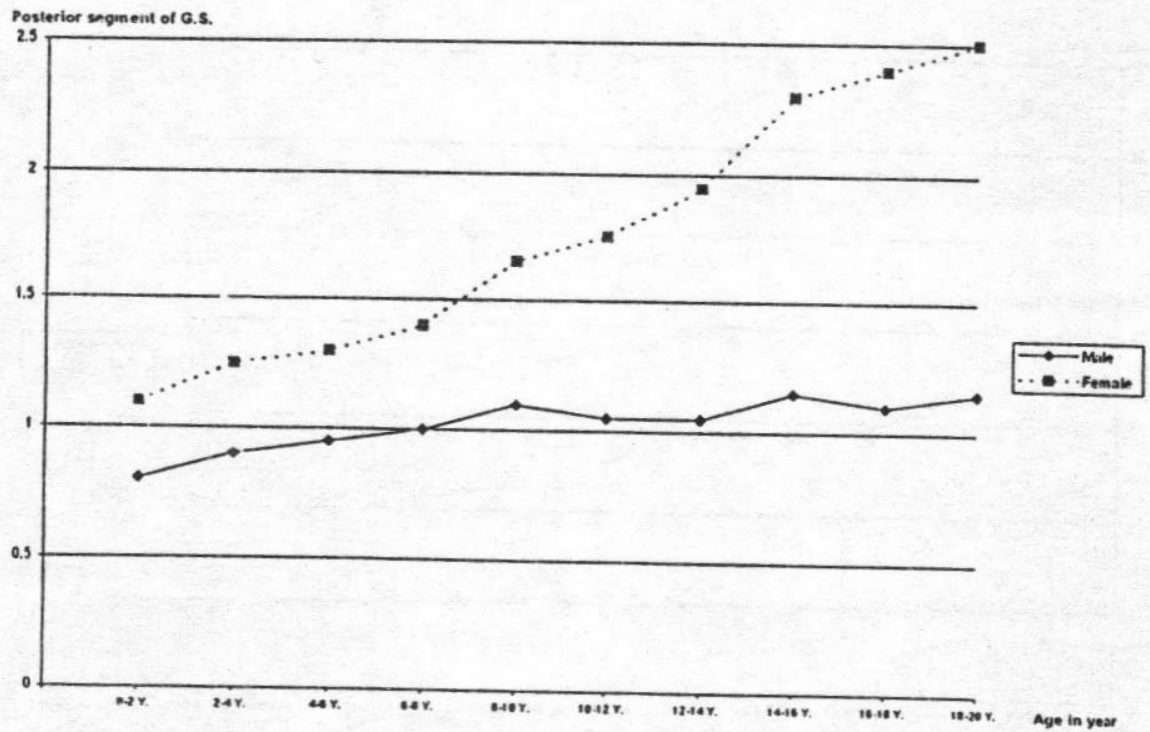

Fig. 9 : Posterior segment of G.S.N. among males and females in different age groups. 


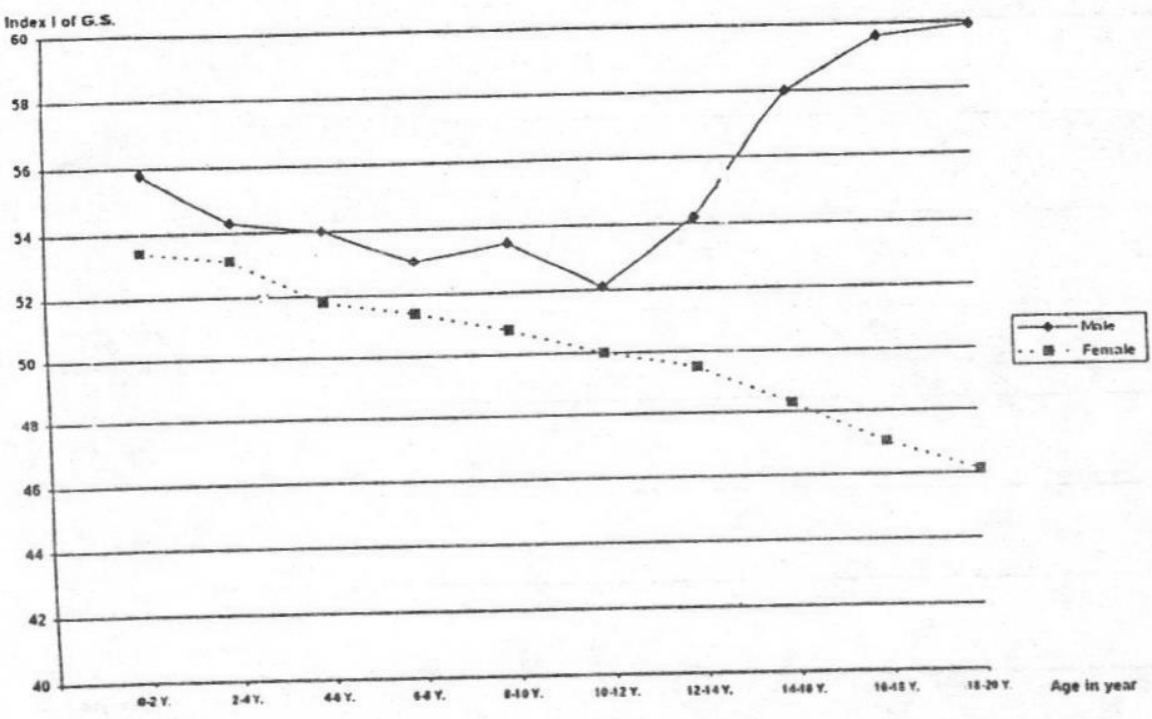

Fig. 10 : Index I of G.S.N. among males and females in different age groups.

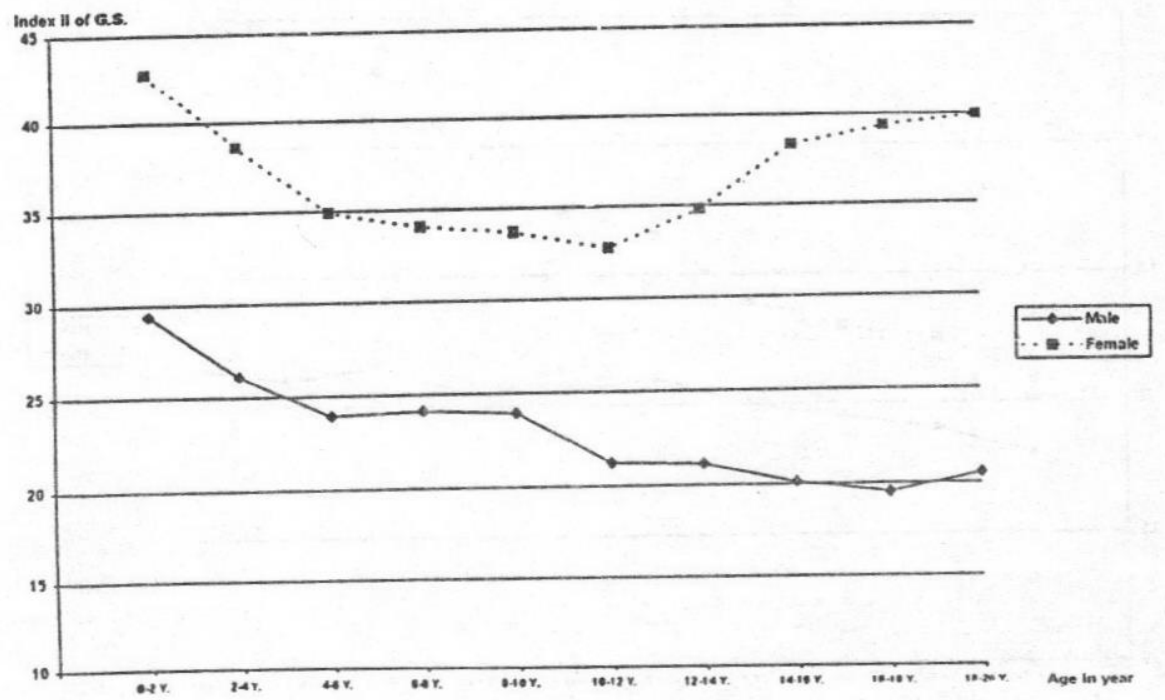

Fig. 11 : Index II of G.S.N. among males and females in different age groups.

Vol. 30, No. 1 \& 2 Jan. \& April, 2000 


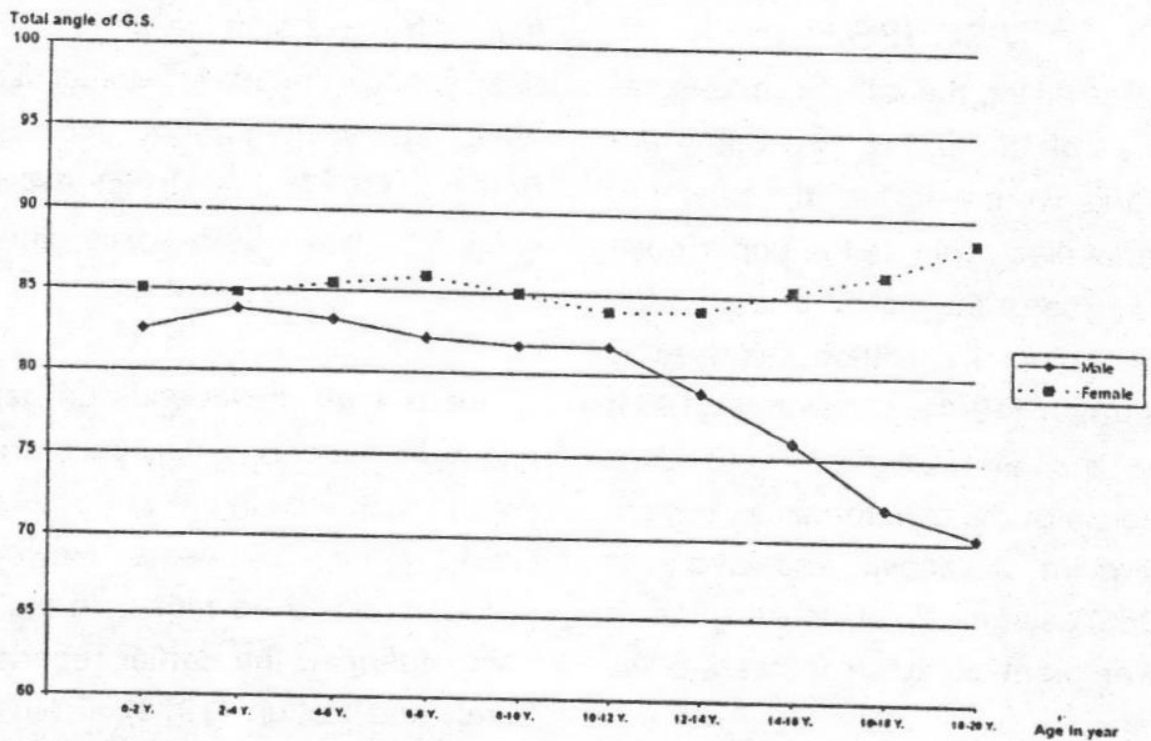

Fig. 12 : Total angle of G.S.N. among males and females in different age groups.

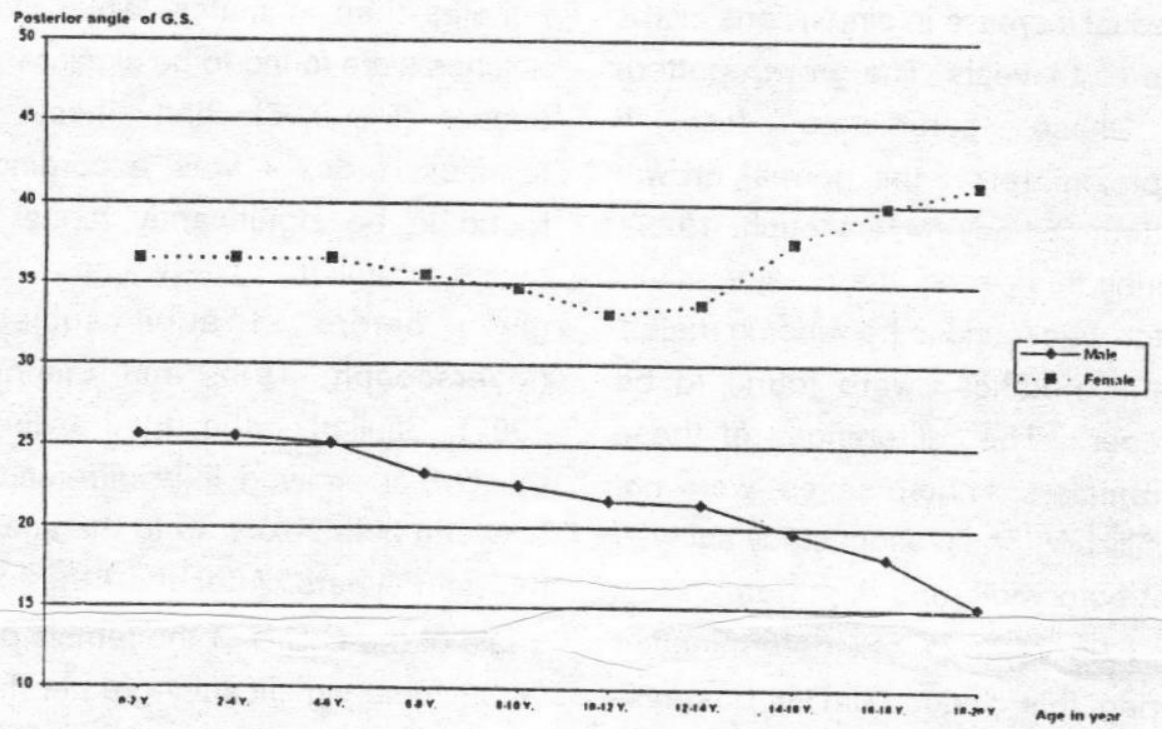

Fig. 13 : Posterior angle of G.S.N. among males and females in different age groups. 


\section{DISCUSSION}

For taking the different measurements of the G.S.N. two bony landmarks were selected: the posterior inferior iliac spine as the upper point and base of the ischial Spine as the lower point. This method was used by Litterman (1941). Davivongs (1963) and Singh and Potturi (1978) used the tubercle of the pyri formis as the upper point. Jovanovic and Zivanovic (1965) used the tip of ischial spine as lower piont of notch instead of its base.

In the present study, both the width and depth of G.S.N. showed gradual increase in dimensions till the age of 14 years. The growth pattern of these parameters followed approximately the normal growth pattern of body (Myerscouph, 1982). During this period, the greater sciatic notch was found to be wider in males. Male notches were found to be deeper. The differences of these paramelers, in both sexes, were not significant. The present study showed that both width and depth are in fact of little value in sex determination during this period Similar boservations have been made earlier by Greutich and Thoms (1945) and Daivong (1963) who have reported that both sexes start life with identical pelves and the major sexual differences appear at puberty. However, Boucher (1957) stated that the distinction between both sexes can be made even during foetal life.

Index I which depends on depth and width the G.S.N. was accordingly not of much help in the sexing of the G.S.N. before 14 years However, it was found to be higher in males. This confirmed the earlier reports ot Singh and Potturi (1978). From the age of fourteen years till 20 years, the greater sciatic notch was found to be significantly wider $(p<0.05)$ in females than in males, while male notches were found to be significantly deeper $(P<0.05)$ than those of females. Index I was accordingly found to be significantly higher in males. Similar observations were given before in adult subjects (Myerscouph, 1982 and Lindner, 1992) Similarly, the total angle of the G.S.N showed little differences between both sexes up to the age of fourteen years. After that, the total anigie of the G.S.N of the femaie peivis become significantly greater than that of the male pelvis. Sexual discrimination of the G.S.N could be made by the use of the posterior seg- 
ment of the G.S.N., index $\|$ and posterior angle.

The fact that the parameters of the posterior segment and index II as good sex determination factor confirms the views of Jovanoic et al., (1968), who stressed the importance of the upper segment of the G.S.N in sex determination. The widening of the G.S.N found in females was found to be is an excellent parameter for discriminating sexual dimorphism at different age groups.

Singh and Potturi (1978) stated that, the adult pelvis, the width and depth of the G.S.N. are useless for determining the sex. The present study showed that beside the value of the depth, width and index I for sexing purposes in adult subjects, the parameters were useful for sex determination as early as fourteen years and to be useless criteria for sexing purpose before that age.

The length of the posterior segment of the width of the G.S.N, index II and posterior angle of the G.S.N was found to be the most useful parameters for sex determination at different ages before puberty. The mean value of the posterior segment of the adult female were more two times those of male.

\section{REFERENCES}

1- Armitage, P. ( 1983) : Statistical methods in medical research. Blackwell scientific puplications, Oxford, London vol. II, p. p. 168-172.

2- Boucher B. (1957) : Foetal sciatic notch; sex differences. Forensic Med., $1: 51$-54.

3- Buchsbaum, H. and Schmidt, I.D. (1993) : Gynaecologic and obstetric surgery, 3rd. ed., Saunders W.B. Company, London, Philadelphia, Montreal, Tokyo, p.p. 25-28.

4- Cunningham, G. G.; MacDonald, P. C.; Leveno, k. J. et al., (1994) : Williams obstetrics. 19th. ed., Vol. 1, Elias Modern Press, London, p.p 29c294.

5- Davivongs, V. (1963) : The pelvic girdle of Australian aborigine; sex differences and sex determination Am. J.

MANSOURA MEDICAL JOURNAL 
Phys. Anthropol., 21: 444455

6- Coldfarb A. F. ( 1968) : Dynamics and abnormalities of puberty. Clin. Obstet. Gynaecol., 11: 769-776.

7- Greutich, W. W. and Thoms, H. (1945) : The growth development of individual girls before, during and after puberty. J. Biol. Med., 17:9197.

8- Hollinshead, W.H. and Rosse, C. (1985) : Textbook of Anatomy 4th ed, Harpet and Row publisher, Bhiladelphia; p.p. $737-740$.

9- Jit, I. and Singh, S. (1966) : Sexing of adult clavicles; Indian J. Med. Res., 54: 551- 571.

10- Jovanovic S. and zivanovic, S. (1965) : The establishment of the sex by greater sciatic notch. Acta Anat. 61: 101.107.

11- Jovanovic, S.; Zivanovic, S. and Lotric, N. (1968) : The upper part of greater sciatic notch in sex determination of pathologically deformed hip bones. Acta Anat., 69: 229-238.

12- Litterman, G.S. (1941) : The greater sciatic notch in American Whites and $\mathrm{Ne}$ gros. Am J. Physic. Anthropol., 28: 99-116.

13- Lindner, H. H. (1992) : Clinical Anatomy. Prentice - Hall international Inc., London, p.p. $458-460$.

14- Llewellyn-Jones, D. (1990) : Fundamental of obstetrics and gynaecology vol . 1, ELBS wolfe Publisher, London, New York and Tokyo, p.p. 219-221.

15- McMinn, R. M. H. (1996) : Last's Anatomy, Regional and Applied, 9th ed., Churchil livingstone, Edinburgh London, New York and tokyo, p.p. 219-221 .

16- Myerscough, P.R. (1982) : Munro Kerr's operative obstetrics. 9th. ed., The English Language Book Society, 
p.p. $38-46$.

17- Singh, S. and gangrade, K. C. (1968) : Sexing of dult clavicles: verification and applicability of demarking points. J. Ind. Acad. Forens. Sci., 7: 20-30.

18- Singh, S. and Potturi. B.R. (1978) : Greater sciatic noth in sex determination. J. Anat., 125: 619-624.

19- Tortora .J. (1995) : Principles of Human Anat., Harper Collins College Publisher, New york, p.p. 162-164.
20- Verneau, R. (1875) : La bassin dans les sexes et dans les races. J. B. Bailliere fils, paris, p. 63 (Cited from: sing, S. and Potturi, B.R. (1978) : Greater sciatic notch in sex determination. J. Anat, 125: 619-624.

21- Williams, P.L.; Bannister, L. H.; Berry, M. M., Collins, P. et al., (1995) : Morphological classification of pelvis Gray's Anatomy 38th ed., Clurchill Livingstone, London, p.p 670674. 


\section{أهمية القياسات المختلفة للشرم الوركى الكبير \\ فى تحديد نوع الجنس حتى عمر العشرين عاماً

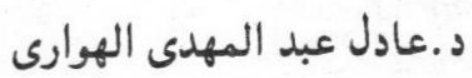

\section{مدرس بتسم التشريح - كلية الطب - جامعة المنصورة}

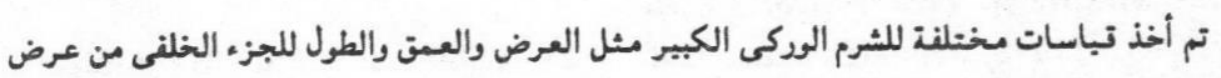

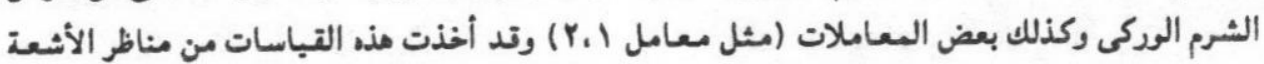

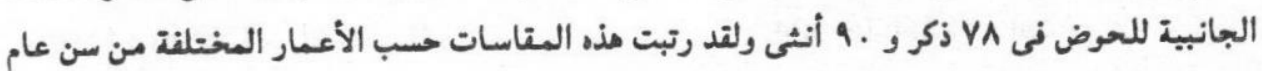

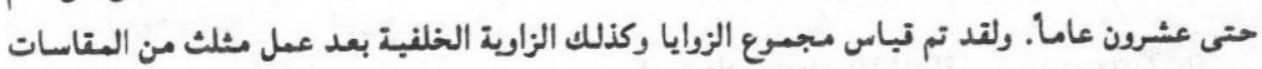

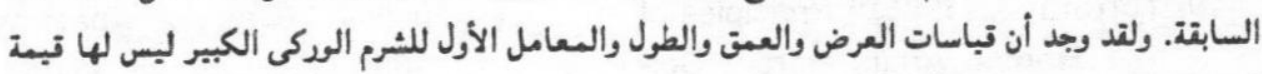

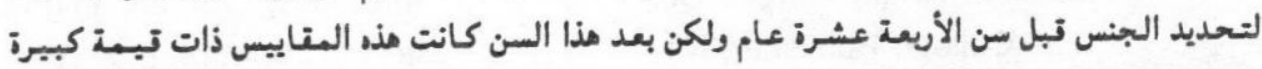

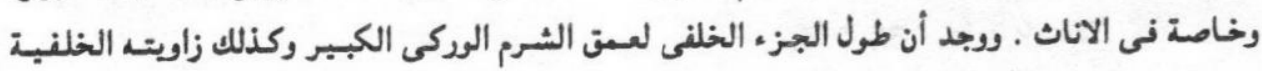

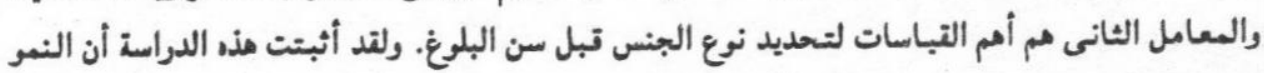

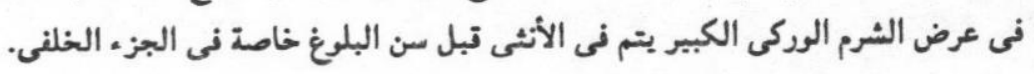

